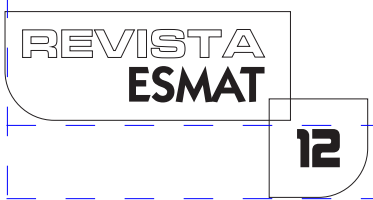

\title{
O INSTITUTO DA MEDIAÇÃO E DA CONCILIAÇÃO SOB A PERSPECTIVA DO NOVO CÓDIGO DE PROCESSO CIVIL
}

THE INSTITUTE OF MEDIATION AND CONCILIATION IN VIEW OF THE NEW CODE OF CIVIL PROCEDURE

Patrícia Francisco da Silva

Mestre em Prestação Jurisdicional e Direitos Humanos pela Universidade Federal doTocantins (UFT), em parceria com a Escola Superior da Magistratura Tocantinense(ESMAT).

\section{RESUMO}

presente artigo tem por finalidade precípua tratar os institutos da mediação e conciliação pela perspectiva do novo Código de Processo Civil, buscando também demonstrar suas inovações e a importância de sua aplicabilidade como forma de construção da cidadania e a inserção de forma definitiva dos referidos instrumentos no ordenamento jurídico brasileiro.

PALAVRAS-CHAVE: Mediação; Conciliação; Autocomposição.

\section{ABSTRACT}

This article is primarily designed to treat the institutions of mediation and conciliation by the new perspective Civil Procedure Code also trying to demonstrate their innovation sand the importance of its applicability as a way of building citizenship and the inclusion definitively these instruments in Brazilian legal system.

KEYWORDS: Mediation; Conciliation; Autocomposition. 


\section{INTRODUÇÃO}

No Brasil, não é exceção o fato de que os conflitos sociais sejam entregues ao Estado, o qual, representado pelo Poder Judiciário, esbarra na morosidade dos processos que se arrastam por anos, sem que, muitas das vezes, alcancem uma solução satisfatória para os litigantes, ansiosos por ver a justiça feita.

A excessiva judicialização dos conflitos, seja pelo fato da disseminação de uma crença de que estes somente se resolvem se acionada a justiça, bem como em razão da litigiosidade contida, com o acesso fácil e a outorga de novos direitos ao cidadão, também contribuem para o congestionamento do Judiciário, imperando a prática do modelo conflitual em busca de uma sentença judicial, que nem sempre traz a paz social.

Desse modo, os sistemas judiciários estatais, no interior do estado de direito, são responsáveis pela pacificação social por meio da imposição das soluções normativas previamente expostas por estruturas normativas escalonadas e hierarquizadas, tal como pensada por Kelsen (|99|). ${ }^{2}$

Nesse diapasão, o ilustre processualista Dinamarco reza:

Não basta alargar o âmbito de pessoas e causas capazes de ingressar em juízo, sendo também indispensável aprimorar internamente a ordem processual, habilitando-a a oferecer resultados úteis e satisfatórios aos que se valem do processo. Um eficiente trabalho de aprimoramento deve pautar-se pelo trinômio (qualidade dos serviços jurisdicionais, à tempestividade da tutela

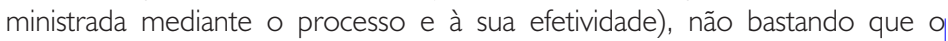
processo produza decisões intrinsecamente justas e bem postas, mas tardias ou não traduzidas em resultados práticos desejáveis; nem sendo desejável uma tutela jurisdicional efetiva e rápida, quando injusta. (2006, p. 69)

Portanto, nessa linha de pensamento, foram criados mecanismos para impedir a morosidade dos processos e contribuir na solução dos conflitos que se encontram normatizados, especialmente na Constituição Federal Brasileira (CFB), que, por seu turno, traz em seu bojo o Princípio do Acesso à Justiça e da Duração Razoável do Processo, princípios estes que, na atual conjetura dos conflitos sociais, acabam por exigir formas eficazes de se obter uma solução que se mostre equilibrada para as pessoas envolvidas num conflito.

Como uma das alternativas de solução de conflitos, tem-se a mediação, pois, até a

' Pensamento retirado da introdução do projeto de mestrado de minha autoria.

${ }^{2} \mathrm{Ou}$ seja, ao judiciário cabe, em não havendo o cumprimento espontâneo das prescrições normativas, a imposição da solução, pois é a ele que compete, com exclusividade, a legitimação de dizer o direito. 
edição do novo Código de Processo Civil, o único instrumento que tratou do instituto da mediação foi a Resolução n I 25, de 2010 , do Conselho Nacional de Justiça.

Tal Resolução institui a Política Pública de tratamento adequado dos conflitos de interesses e, ainda, impõe a criação pelos tribunais dos centros de solução de conflitos e cidadania e regulamenta a atuação do mediador.

Quanto à conciliação, esta veio consagrada no Código de 1973; porém, no atual Código de Processo Civil, verifica-se uma ênfase dada pelo legislador ao aludido instituto, buscando a celeridade processual e a pacificação nas soluções dos conflitos sociais.

Exatamente a seletividade do sistema jurídico brasileiro e a visão reducionista de acesso à justiça - que o identifica com o acesso ao Poder Judiciário - motivam a investigação do que ora se apresenta.

Considerando-se as lições de Santos (1996, p. 32), existe no País uma demanda suprimida por justiça, representada por indivíduos que não conhecem seus direitos ou mesmo os conhecendo sentem-se incapazes para reivindicá-los. Chama a atenção ao dizer que olhar para essa legião de pessoas significa proceder a uma revolução democrática da justiça.

Portanto, neste trabalho, o escopo consiste em demonstrar as mudanças provocadas pela edição do novo Código de Processo Civil quanto ao instituto da mediação e conciliação, a fim de demonstrar os benefícios que possam advir dessas mudanças.

\section{BREVES CONSIDERAÇÕES}

Ainda que o presente artigo tenha enfoque um tanto prático na mediação e na conciliação, pela perspectiva do novo Código de Processo Civil, importante apresentar resumidamente uma contextualização histórica dos referidos institutos no Poder Judiciário.

A preocupação com o acesso à justiça acompanha a evolução das sociedades. Observa-se que no século XII abriu-se a possibilidade de um estado de direito, um estado de cidadãos, regido por uma Carta de Direitos, a chamada Era de Direitos.

Nos séculos XVIII e XIX, o acesso à justiça incluía a garantia formal de os indivíduos ajuizarem ou responderem a uma ação, concepção esta conforme os ditames do modelo de Estado liberal e com a filosofia estritamente individualista de direitos da época.

Com o advento do Estado social, com a busca da transição para o socialismo, aparecem, no séc. $X X$, os movimentos de expansão do acesso à justiça, exigindo-se, a partir de então, a atuação positiva do Estado para assegurar materialmente o acesso aos direitos individuais e sociais proclamados na Constituição Federal a todos os cidadãos.

Com o movimento do acesso à justiça iniciado nos anos 70, reclamava-se por alterações no sistema que impulsionassem um acesso à justiça efetivo, na perspectiva do 
própriojurisdicionado.

Portanto, com o objetivo de se garantir a igualdade material no acesso à justiça, tornou-se imperioso o estudo de meios alternativos de resolução de conflitos, principalmente no que concerne à conciliação e à mediação como instrumentos de ampliação do acesso à justiça.

Insta frisar que especificamente a mediação, sendo elemento característico dos juizados de pequenas causas nos Estados Unidos, fortemente veio a influenciar o legislador brasileiro que acabou por instituir a conciliação em seu sistema dos juizados especiais.

Não obstante, a autocomposição inserida pelo legislador no ordenamento jurídico, especificamente na Lei n 9.099, de 1995, diferenciou-se fortemente daquela prevista pelo ordenamento norte-americano, tendo em vista ter dado menos ênfase às técnicas e ao procedimento a ser seguido.

Até a edição do novo Código de Processo Civil, o único instrumento que tratou do instituto da mediação foi a Resolução n ${ }^{\circ}$ | 25, de 20 l 0, do Conselho Nacional de Justiça.

Tal resolução institui a Política Pública de tratamento adequado dos conflitos de interesses e, ainda, impõe a criação pelos tribunais dos centros de solução de conflitos e cidadania e regulamenta a atuação do mediador.

Nessa linha de pensamento, o novo Código de Processo Civil foi estruturado, agora de forma mais evidente, buscando estimular a utilização dos meios alternativos de solução de conflitos, e mais afeito a técnicas e procedimentos estabelecidos na Resolução CNJ n 1 25/20 10.

Dentre as inovações trazidas no novo CPC, uma delas diz respeito à inserção do instituto da Mediação e Conciliação na audiência preliminar, por se constituir potencial gerador de grandes repercussões não só no ordenamento jurídico, mas também na sociedade. Isso porque por meio desses institutos é possível que as partes resolvam seus conflitos de forma autônoma e, muitas vezes, definitiva, colaborando ainda para o desafogamento do poder judiciário e para a fomentação de uma cultura de paz.

\section{CONFLITO E PROCESSOJUDICIAL}

Pode um conflito ser definido como um estado em que duas ou mais pessoas discordam em razão de interesses ou metas individuais e percebidos como mutuamente incompatíveis.

Normalmente, costuma-se pensar no conflito como um acontecimento negativo nas relações sociais, por isso, em treinamentos de técnicas de mediação, conforme cita Souza (2009, p. 27), os participantes são estimulados a indicar a primeira palavra que Ihes vem a cabeça e muitas das vezes são citados termos como guerra, violência, processo.

Processualistas, como Zamorra e Castillo ( 199 | , p. 238), defendem que o processo 
rende, com certa frequência, muito menos do que deveria, considerando-se os defeitos procedimentais que resultam num processo lento, moroso, fazendo com que as partes o abandonem.

A esses chamados defeitos procedimentais do processo, verifica-se que o processo judicial aborda o conflito como se fosse um fenômeno jurídico, e, ao tratar exclusivamente dos interesses juridicamente tutelados, exclui características importantes quanto ou até mais relevantes que os juridicamente tutelados.

Assim, quando um juiz profere uma decisão determinando que o pai pague alimentos ao filho, põe fim, para fins de dizer o direito - o chamado direito positivado - a determinado litígio; no entanto, além de não resolver a relação conflituosa, muitas vezes pode instigar novos conflitos, pois pode criar novas dificuldades para os pais e filhos. Portanto, indubitável que em muitas situações o operador do direito não pode deixar de fora o componente fundamental do conflito e sua resolução, qual seja, o ser humano.

Não raramente, os conflitos não podem ser resolvidos exclusivamente por abstrata aplicação da técnica de subsunção.

Assim, a partir de uma definição mais ampla da mediação e da conciliação, pode-se afirmar que, em certo sentido, todas as pessoas são mediadoras ou conciliadoras, isso porque em algum instante de suas vidas, já intervieram numa discussão seja na família seja no trabalho, auxiliando outras tantas a resolverem um problema.

\section{NORMAS E PRINCÍPIOS QUE REGEM A MEDIAÇÃO EA CONCILIAÇÃO}

Por meio da Resolução n I 25, de 20 I0, do Conselho Nacional de Justiça, criou-se no Brasil a política pública de tratamento adequado de conflitos, tendo em vista que a solução negocial não é apenas um meio eficaz e econômico dos litígios, visando tão somente à diminuição de processos, mas, sobretudo, num importante instrumento de desenvolvimento da cidadania.

Portanto, o incentivo à autocomposição pode ser entendido, conforme ensinamentos de Didier (20 I 5, p. 274), como um reforço da participação popular no exercício do poder - no caso o poder de solução de litígios.

Nesse seguimento, importante mencionar que o instituto da mediação é, de acordo com o art. 166 do CPC-2015, informado pelos princípios da independência, da imparcialidade, do autorregulamento da vontade, da normalização do conflito, da confidencialidade, da oralidade, da informalidade, da decisão informada. Embora o princípio da cooperação não esteja explícito no referido artigo, entende-se que deva ele também ser considerado, o que se demonstrará adiante.

De um lado, pode-se afirmar que o princípio da independência fundamenta a atitude do mediador, que deve atuar com liberdade, sem que sofra influência interna ou externa. Nessa linha de pensamento pode o mediador se recusar a suspender a sessão se ausentes os pressupostos necessários para o seu bom desenrolar. 
No mesmo sentido, indispensável é a imparcialidade ao bom desenvolvimento da mediação e da conciliação, porque o mediador e o conciliador não podem ter interesse no conflito.

Ainda, tratando dos princípios alusivos aos institutos tratados neste trabalho, tem-se, como um dos mais importantes, o do autorregramento da vontade, que se constitui em corolário da liberdade, isso quer dizer que tudo deva ser pensado para que as partes definam a melhor solução para o seu problema. ${ }^{3}$

Infere-se que o respeito à vontade das partes é salutar para que o conflito seja solucionado, portanto, ao mediador ou ao conciliador é proibido constranger qualquer das partes.

Por conseguinte, a confidencialidade diz respeito ao fato de o mediador e o conciliador terem o dever de sigilo profissional, isto é, não poderão divulgar ou prestar depoimento acerca dos fatos tratados na mediação ou na conciliação.

Dentre as alterações trazidas pelo novo Código, uma delas em particular diz respeito à inserção mais contundente dos princípios da oralidade e informalidade que conduzem a mediação, provocando mais leveza sem o ritual próprio de um processo, exigindo do mediador que utilize linguagem simples, acessível ao leigo, além de vestimentas informais, desvinculados do dia a dia forense.

Ademais, é fundamental que as partes sejam bem informadas, isso porque o consenso somente pode ser obtido se houver a compreensão do problema e das consequências dele advindas.

Finalmente, a cooperação entre os envolvidos no processo pode ser reconhecida como o modelo coexistencial comparticipativo de processo como técnica de construção de um processo civil democrático e conforme a Constituição Federal.

Portanto, o modelo cooperativo ${ }^{4}$ tem por característica a articulação dos papéis processuais do juiz e das partes, a fim de harmonizar a eterna tensão entre liberdade individual e o exercício do poder pelo Estado.

Verifica-se que alguns desses princípios, como a oralidade, a informalidade e autorregulação da vontade, trazem mais leveza, sem todo aquele ritual e formalidade próprios da atuação jurisdicional.

\footnotetext{
${ }^{3}$ Defender o autorregramento da vontade no processo não significa defender um processo estruturado em um modelo adversarial. $\bigcirc$ respeito à liberdade convive com a atribuição de poderes ao órgão jurisdicional, até porque o poder de autorregramento da vontade no processo não é limitado. Tal princípio visa à obtenção de um ambiente processual em que o direito de autorregular-se possa ser exercido pelas partes sem restrições irrazoáveis ou injustificadas.

${ }^{4} \mathrm{O}$ processo cooperativo não é processo que ignora a vontade das partes, tampouco considera o juiz como mero espectador.
} 
Desta feita, importante destacar que o mediador e o conciliador devem comunicarse em linguagem simples e acessível aos envolvidos; de outro modo, todos devem participar e definir suas próprias normas para a resolução do conflito.

Tais aspectos são salutares para permitir um diálogo mais franco, enfatizando a informalidade, a oralidade e a autorregulação da vontade, instrumentos necessários para a inserção do instituto de mediação e conciliação como meios alternativos de resolução de conflitos na cultura jurídica brasileira.

\section{DISTINÇÕES E SEMELHANÇAS ENTRE A MEDIAÇÃO E A CONCILIAÇÃO NO NOVO CPC, ASPECTOS IMPORTANTES DA MEDIAÇÃO E DA CONCILIAÇÃO}

Tanto uma técnica como a outra podem ser apresentadas como os principais exemplos de "solução alternativa de controvérsias" (Alternative Dispute Resolution $A D R)^{5}{ }^{5}$ No entanto, existem diferenças tênues entre os dois institutos, sendo consideradas como técnicas distintas de autocomposição pelo próprio CPC, consoante se verificarão adiante.

De outra banda, as diferenças são tênues entre os dois institutos, porque a própria doutrina as considera como técnicas distintas de autocomposição.

O conciliador tem posicionamento mais ativo no processo de negociação, podendo propor soluções para o conflito ou litígio. Já o mediador tem papel diverso, competindose-lhe servir de guia de veículo de comunicação entre os envolvidos, constituindo-se num facilitador do diálogo, auxiliando-os a compreender as questões. Interessante notar que na mediação, diferentemente da conciliação, o mediador não propõe a solução para o conflito, decorre disso que os envolvidos em conjunto constroem uma solução para este.

No novo CPC, o art. 165, parágrafo $2^{\circ}$, legitima tal diferença ao estabelecer que o conciliador que atuará preferencialmente nos casos em que não houver vínculo anterior entre as partes, poderá sugerir soluções para o litígio, sendo vedada a utilização de qualquer tipo de constrangimento ou intimidação para que as partes conciliem.

Com relação à mediação, fundamenta o aludido artigo que o mediador atuará preferencialmente nos casos em que houver vínculo anterior entre as partes, auxiliará os interessados a compreender as questões e os interesses em conflito, de modo que eles possam, pelo restabelecimento da comunicação, identificar, por si próprios, soluções consensuais que gerem benefícios mútuos.

${ }^{5}$ Expressão utilizada no EUA para nomear os meios alternativos de solução de conflitos. 
Observa-se que novo Código, diferente do Código de 1973, que nem faz menção à mediação, vedam-se, em ambos os institutos, o constrangimento ou intimidação, para que as partes solucionem o conflito.

Saliente-se, ainda, que se tem por grande inovação o fato de que a mediação e a conciliação podem ocorrer em câmaras públicas institucionais, com vínculo com o tribunal, bem como em ambiente privado, como no caso de convênio com os Núcleos de Prática das Universidades, conforme estatuído nos artigos 167, I74 e 175 do CPC.

Verifica-se, no novo Código, que a mediação e a conciliação podem se dar tanto judicial como extrajudicialmente. No primeiro caso, os mediadores e conciliadores são tratados como auxiliares da justiça, nos termos do art. |48, II; 170 e 173, II, do CPC.

Essa qualificação é salutar, uma vez que deverão ser aplicadas as regras a esse auxiliar de justiça, como, por exemplo, o impedimento e a suspeição.

Cabe, nesse contexto, verificar como inovação que a conciliação e a mediação podem ser praticadas pro bono, ou seja, como trabalho voluntário, consoante especifica o art. 169, parágrafo $1^{\circ}$, do CPC.

\section{AUDIÊNCIA PRELIMINAR DE CONCILIAÇÃO E MEDIAÇÃO}

Outra novidade trazida pelo novo CPC diz respeito à atual audiência preliminar, que consistirá em audiência de conciliação ou mediação.

Determina o novo CPC, em seu art. 334, que não sendo o caso de indeferimento da petição inicial ou de improcedência liminar do pedido, deve o juiz determinar a citação do réu e designar audiência de conciliação ou mediação.

Infere-se que a audiência será de conciliação ou mediação a depender do conflito a ser solucionado e, como já dito alhures, cabe ao Código dizer quando será o caso de aplicar-se a conciliação ou a mediação.

Outrossim, em dissonância com o CPC, de 1973, o novo Código traz que a audiência de conciliação ou mediação ocorrerá antes da oferta de defesa pelo réu, e o mais interessante é que a audiência deve se realizar no centro judiciário de solução consensual de conflitos, a não ser em casos excepcionais em que a audiência poderá ocorrer em juízo.

Pela importância do tema, trazem-se ao presente trabalho as duas hipóteses em que a audiência de conciliação ou de mediação não deverá ser designada. Nos termos do art. 334, parágrafos $4^{\circ}$ e $5^{\circ}$, do novo CPC, o legislador preferiu não impor a audiência no caso em que ambas as partes manifestam expressamente o desinteresse pela solução do conflito pela mediação ou conciliação, buscando eliminar a possibilidade de a audiência não se realizar apenas porque uma das partes não a deseja, tudo em conformidade com o autorregramento da vontade.

Ademais, não será marcada audiência de conciliação ou mediação no processo em que não se admita a autocomposicão, como, por exemplo, com relação aos chamados direitos indisponíveis. 


\section{CONCLUSÃO}

O acesso à justiça no Brasil, até o presente momento, confunde-se com o acesso ao Poder Judiciário.

Para muitos brasileiros, o acesso à justiça é quase que inexistente, senão difícil, tendo - Poder Judiciário pouca competência para solucionar conflitos, além de ser moroso e caro.

Até então, o ordenamento jurídico brasileiro exigia uma revolução na conceituação de acesso à justiça com a superação dos referidos obstáculos transformando-se em realidade a justiça para todos.

Desse modo, fez-se a revolução por meio da Resolução no 125 do CNJ, de 20 I0, e por meio de um código mais democrático, com a promessa de que daqui em diante é possível a realização de uma justiça coexistencial, pois o novo CPC foi estruturado para fomentar a autocomposição. Veja-se que há um capítulo somente para regular a mediação, como é o caso dos artigos I 65- 175.

Também com o propósito de estimular os meios alternativos de solução de conflitos, o CPC inseriu no rol das normas fundamentais do processo civil os parágrafos $2^{\circ}$ e $3^{\circ}$, os quais informam que o Estado promoverá sempre que possível a solução consensual dos conflitos e que a mediação e outras formas de autocomposição deverão ser estimuladas por advogados, juízes.

A mediação e a conciliação constituem-se em importantes instrumentos de pacificação social, uma vez que importa em autocomposição das partes que, ao final, chegarão à conclusão de que é possível a solução do conflito pelas próprias partes envolvidas, verificando-se o quão importante é a participação da sociedade na construção de um mundo menos adversarial.

Assim, a construção de um sistema descentralizado, acessível e informal de resolução de conflitos, como meio de se ter acesso à justiça, focado na mediação e conciliação, seja pelo próprio Estado ou pela sociedade civil, dentre elas as universidades, deve orientar um novo conceito de acesso à justiça que inclua, especialmente, a oferta de informação à população a respeito de seus direitos.

Ressalte-se que o novo CPC não objetiva retirar do Judiciário seu principal papel, qual seja, dizer o direito de justiça, mas que sirva também como instrumento de resguardo para a resolução dos conflitos, o que se verifica no novo CPC, reclamando a desjudicialização dos procedimentos e o estímulo à adoção de outros meios de resolução de conflitos que privilegiem a utilização da mediação e da conciliação.

Embora a mediação e conciliação contribuam para a diminuição de demandas judiciais ou aceleração dos processos, deve-se buscar enxergar que, com a criação de tais institutos e de forma expressa inseridos no CPC, acabam por incentivar a participação do indivíduo na elaboração da norma jurídica que regulará especificamente o seu caso, respeitando o autorregramento e a liberdade das partes. 


\section{REFERÊNCIAS}

ALMEIDA, Tania. Mediação de conflitos e facilitação de diálogos: aportes teóricos para diálogos com múltiplas partes. In: CUNHA, José Ricardo; NORONHA, Rodolfo. Mediação de conflitos comunitários e facilitação de diálogos: relato de uma experiência na maré. Rio de Janeiro: FGV. 2010. Disponível em: <http://bibliotecadigital.fgv.br/dspace/bitstream/handle/I 0438// 03 | 4/Media\%C3\%A 7\%C3\%A30\%20de\%20conflitos\%20comunit\%C3\%AI rios\%20e\%20facilita\%C3 \%A7\%C3\%A3o\%20de\%20di\%C3\%Allogos.pd? sequence=I >. Acesso em 17 jun. 2015.

BOLZAN, José Luis. Características e princípios da mediação que estão implícitos na chefia indígena. Porto Alegre: Livraria do Advogado, 1999.

BRASIL. Constituição da República Federativa do Brasil de 1988. Brasília, DF, 5 out. 1988 . Dis pon ível e m : <http://www.planalto.gov.br/ccivil_03/constituicao/constituicao.htm>. Acesso em7 jun. 2015.

Lei n 13.105, del6 de março de 20 I5. Institui o Código de Processo Civil. Brasília, DF, 16 mar. 2015. Código de Processo Civil. Disponível em: <http://www.planalto.gov.br/ccivil_03/_Ato20 I 5-20 I8/20 I 5/Lei/LI3 I05.htm >. Acesso em 7 jun. 2015.

CONSELHO NACIONAL DE JUSTIÇA. Resolução N 125 de 29/I I/20I0. Dispõe sobre a Política Judiciária Nacional de tratamento adequado dos conflitos de interesses no âmbito do Poder Judiciário e dá outras providências. Brasília, DF, 29 nov. 2010. Disponível em: < http://www.cnj.jus.br/busca-atos-adm?documento $=2579>$. Acesso em7 jun. 2015.

DIDIER, Fredie Jr., Curso de direito processual civil: introdução ao direito processual civil, parte geral e processo de conhecimento. Salvador(BA): JusPodivm, 2015.

DINAMARCO, Cândido Rangel. A instrumentalidade do processo. São Paulo: Malheiros, 2005.

DURÃO, Aylton Barbieri. A crítica de Habermas à dedução transcendental de Kant. Londrina: EDUEL, 1996.

DUTRA, Delamar V. Kant e Habermas a reformulação discursiva da moral kantiana. Porto Alegre: EDIPUCRS, 2002. 
ESPADA, Paulo Eduardo Christino. A ação comunicativa na mediação e arbitragem. Âmbito Jurídico, Rio Grande, ano 10, n. 47, nov. 2007. Disponível em: $<$ h $\mathrm{t}$ t p : / / w w w a $\mathrm{w}$ b i $\mathrm{t} 0$ juridico.com.br/site/index.php?n_link=revista_artigos_leitura\&artigo_id=2369>. Acesso em lo jun. 2015.

FIORELLI, José Osmir; FIORELLI, Maria Rosa; MALHADAS JUNIOR, Marcos JulioOlivé. Mediação e solução de conflitos: teoria e prática. São Paulo: Atlas, 2008.

HABERMAS, Jurgen. Consciência moral e agir comunicativo. Rio de Janeiro: Tempo Brasileiro, 1989.

. Racionalidade e comunicação. Lisboa: Edições 70, 1996.

KELSEN, Hans. Teoria pura do direito. São Paulo: Martins, I991.

ROUANET, Paulo Sérgio. Ética lluminista e ética discursiva. Rio de Janeiro: Revista Tempo Brasileiro, 1989.

SANTOS, Boaventura de Sousa. $\bigcirc$ acesso à justiça. In: Justiça: promessa e realidade: acesso à justiça em países ibero americanos. Rio de Janeiro: Nova Fronteira, 1996.

SILVA, Luiz Marlo de Barros. O acesso limitada à justiça e soluções alternativas. Porto Alegre: Livraria do Advogado, 2005.

TEMPO BRASILEIRO. Rio de Janeiro: Revista Trimestral de Cultura, 1989.

ZAMORA Y CASTILLO, Niceto Alcalá. Processo, autocomposição autodefesa. Cidade do México: Ed. Universidade Autonóma Nacional de México, I99|.

WARAT, Luiz Alberto. Em nome do acordo: a mediação no direito. Associação Latino Americana de Mediación, Metologia y Enseñanza Del Derecho, 1998.

Recebido em: $21 / 11 / 2016$ Aprovado em: 26/12/2016 
